\title{
TOOLS FOR THE ARMY GENERAL PRACTITIONER
}

\author{
Lieutenant-Colonel J. G. WALLER, \\ M.B., Ch.B., M.R.C.G.P., D.C.H., D.T.M.\&H., R.A.M.C. \\ Medical Reception Station, Antwerp
}

SUMMARY: Some instruments found by the author to be of value in general practice are described and illustrated. Discussion includes the question of availability and supply.

\section{Introduction}

From time to time the Army general practitioner may find himself involved in exercises with troops or in limited war operations. In both instances he may suffer the irritation of lacking the tools for the job unless he has considered the problem beforehand. Particularly when operating in territories beyond the range of military hospitals, as I have done during the last few years in Libya, Kenya, Sarawak, Sabah and Belgium, it is more than ever necessary to be properly equipped. To have to refer a simple case to a local hospital merely because of lack of foresight is an embarrassment to be avoided.

Even when working in a normally equipped medical centre, some additions to scale will lend a professional polish, and give the user more satisfaction and pride in the job.

The following is not intended to be comprehensive.

\section{Auriscope/ophthalmoscope}

\section{Some useful instruments}

Good illumination of the part to be examined is of the first importance, and next to the mouth, the ear is most frequently inspected. A general practitioner cannot function properly for a single day without an auriscope, and it is worth devoting some attention to this instrument. Figure 1 shows my own battered auriscope set, purchased in 1949 . These cheap sets are unsatisfactory, or rather unsatisfying, to use, because the switch gear and mating of the auriscope head with the handle are imprecise, and the light will flicker. The aural specula, which in a given case have probably been cannibalised from another set, are either too tight or keep falling on to the floor, and there is often difficulty in obtaining fresh batteries, that is, batteries which have not already exceeded their shelf life.

The problem used to be simply and cheaply solved when I was serving in India, where a tubular auriscope was provided, with an opening in the side to catch the sunlight. At night, an assistant had to shine his torch through the hole.

Today it is probably worth investing in a precision auriscope such as the model by Heine shown in Figure 2, and while doing so one should also consider including for the sake of completeness the very versatile and superbly made ophthalmoscope head

Editor's note.

This article of necessity represents the personal view of the author based on his own experience. We would welcome the opinions of others, so if you have views to offer please write to us. 
J. G. Waller

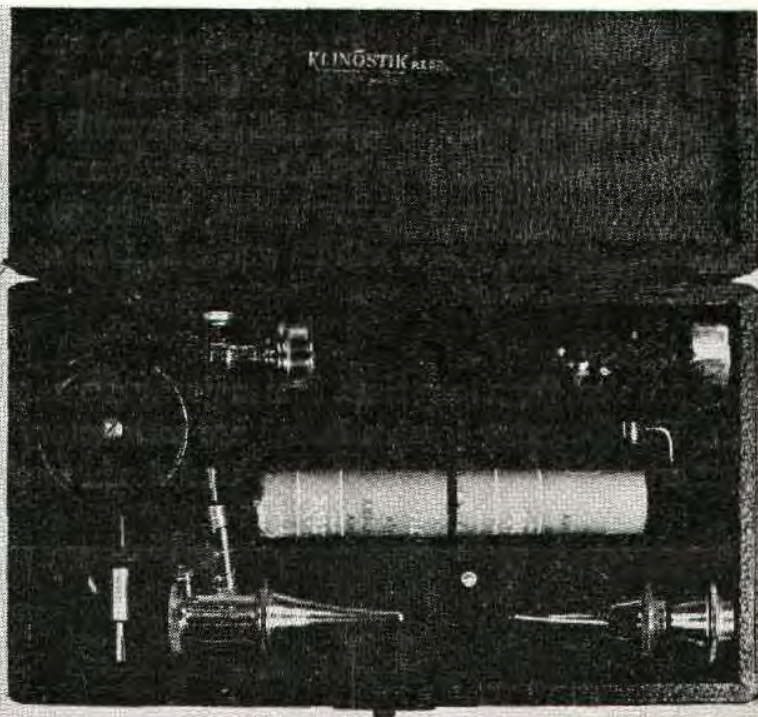

Fig. 1.

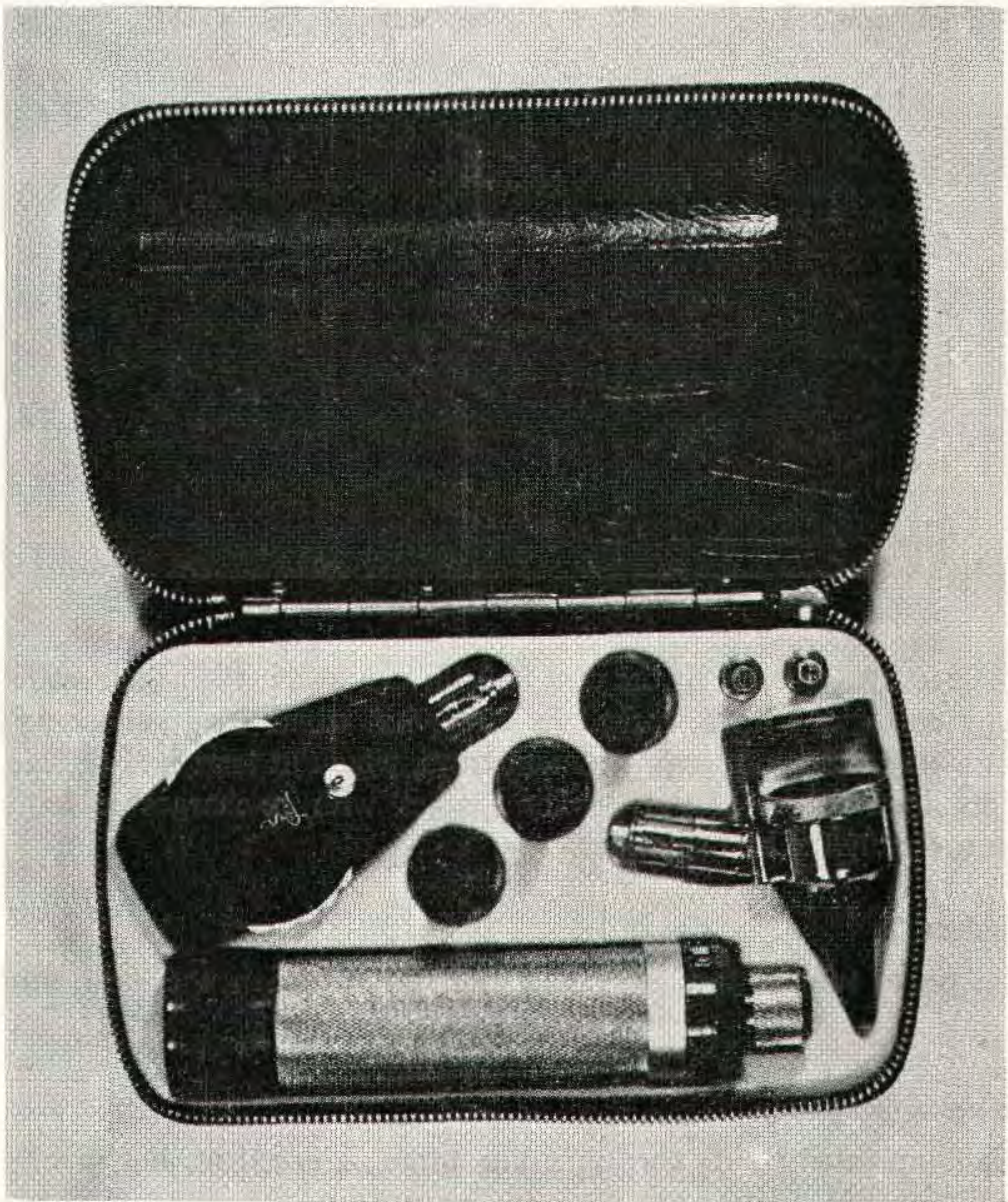

Fig. 2. 
(which adds little to the weight but doubles the cost) — even though quite good ophthalmoscopes are available from Service sources. The battery handle is of the re-chargeable type, or alternatively dry batteries may be specified. The trouble is, though, corrosion from unsuitable dry batteries can begin very quickly, and is almost impossible to arrest. This is the only expensive item mentioned in my review, but in my opinion, considering the pleasure and satisfaction gained, it is worth its weight in Deutschemarken.

\section{Throat torcires}

These have been a problem for a long time. The majority are unreliable, particularly as regards the switch. The focussing torches issued are satisfactory to use, as long as their switches last, but are too heavy for the pocket. Useful pen torches (Fig. 3 bottom)

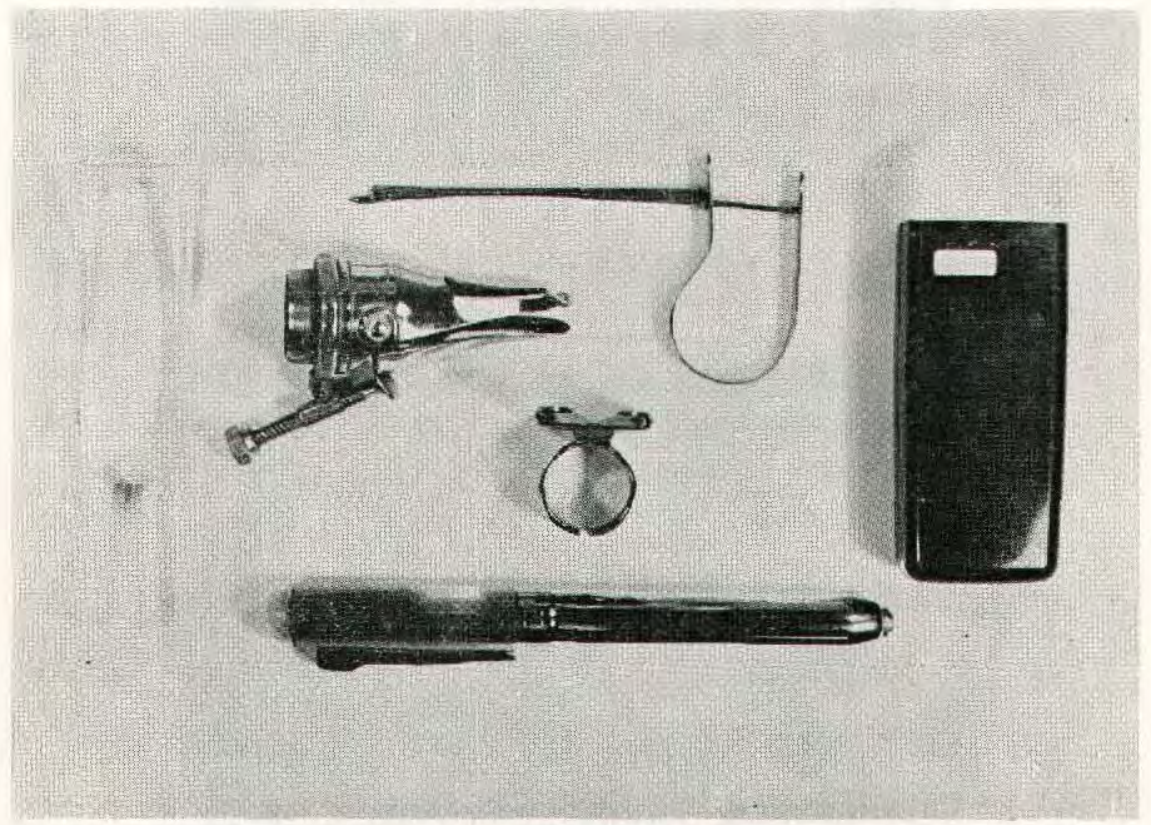

Fig. 3,

can be obtained at a quarter of the cost and thrown away when their switches break. At the other extreme, I have worked in a hospital which used rubber covered Ever Ready motorists torches on the instrument trays, which at least had the merit of reliability. Now light-weight plastic pocket torches with re-chargeable batteries (Fig. 3 right) are probably the best solution.

\section{Spatula holders}

To clip on to tubular torches, I find more trouble than they are worth (Fig. 3 centre).

\section{Plastic transparent spatula}

This is illuminated by its corresponding torch, is excellent, but involves another step in sterilizing (Fig. 3 left). 


\section{Adjustable aural speculum}

Shown in Figure 3 is occasionally useful.

\section{Foreign body extractor}

The foreign body extractor fulfils a fairly rare, but then most welcome, function (Fig. 3 top). It is intended for removing vegetable foreign bodies such as dried peas from the external auditory meatus. It is incorrect to extract these by syringing, unless with olive oil, as if the attempt fails, the resultant swelling of the pea will cause painful impaction. Squeezing the handle of my extractor after passing it beyond the obstruction erects the serrated tip, whereupon it may be withdrawn, It may also be used for foreign bodies in the nasal passages. In the past eighteen months I have twice removed plastic beads from the noses of young children with this instrument. On a third occasion when I was not available the patient had to be sent to hospital, resulting in a fee of 481 Belgian francs-enough to provide an instrument for both our surgeries.

\section{Ear syringes}

I personally dislike the rubber ear syringes provided and never use them. I find it impossible to exert proper control and pressure, so that, far from being safer, they are more dangerous. At least one assistant is required, and even then one gets a lot of air bubbles, while the rapid deterioration of rubber is always a trouble, especially in the tropics. If they are used, they should be of the proper design as shown in Figure 4. One should note the curved and tapered plated metal nozzle, the spoon-shaped support against the rubber bulb, and the domed foot on the end of the tubing to be immersed in water.

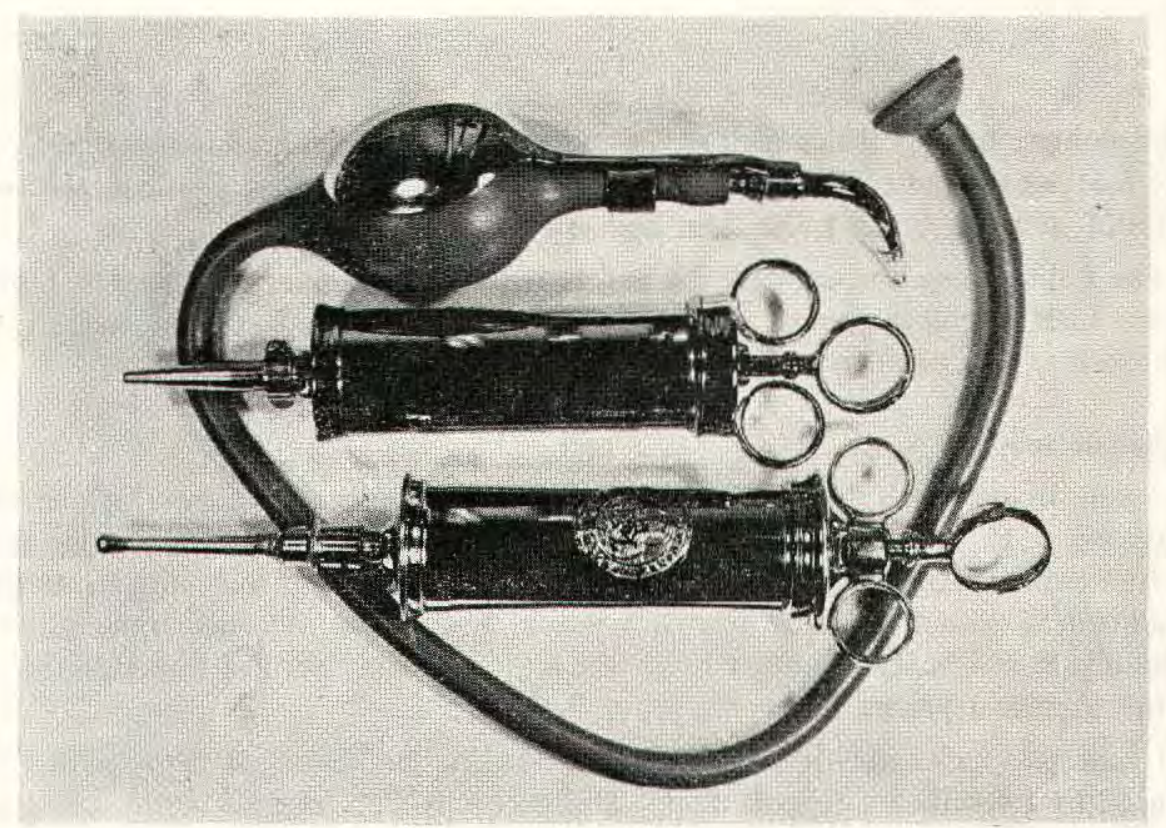

Fig. 4. 
I never delegate this task to juniors, nor allow others to use my piston type ear syringe by Thackray (Fig. 4 centre), so that it remains smooth working. Note its neat nozzle, compared with the issued specimen below which obscures the view of the meatus.

\section{Eustachian catheters}

Occasionally one may wish to insufflate the pharyngotympanic tube, for example, in a case of tinnitus from simple obstruction, and possession of a few graded catheters (Figure 5) will avoid sending the patient to hospital, probably recurrently. One needs

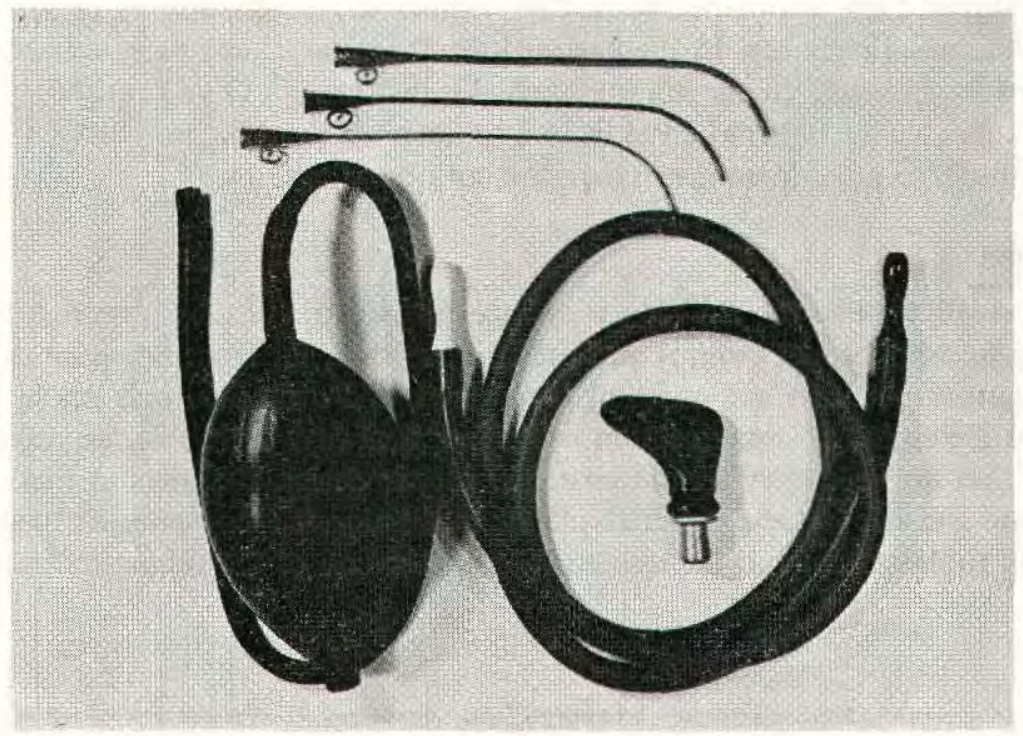

Fig. 5.

a good Politzer bag for attachment to the catheter, and tubing and nozzles (Fig. 5 right) for connecting the patient's ear to one's own. The rubber nasal piece sometimes avoids the use of catheters but is rather ' hit and miss'.

The Politzer bag and catheter are excellent for the secondary purpose of blowing powder, such as chloramphenicol, into the external auditory meatus in treatment of otitis externa, as a powder insufflator is not on the Medical Centre scale.

\section{Ophthalmic loupe}

Again, in eye work illumination is of prime importance, and here also one needs a magnifier. The binocular type with a head-band is convenient, leaving the hands free. In National Health Service practice we used to keep one in each surgery, but they are difficult to obtain in Army general practice, and indeed anywhere other than the ophthalmic department of military hospitals, although many corneal foreign bodies are seen in Casualty departments.

I have now given this up, as I am interested in the very neat map-reading light produced by Ever Ready (Fig. 6 right). This has only $2 \frac{1}{2} \mathrm{x}$ magnification, but $\mathrm{I}$ have asked the manufacturers if they can produce one with the 8 or $10 \mathrm{x}$ magnification needed, 


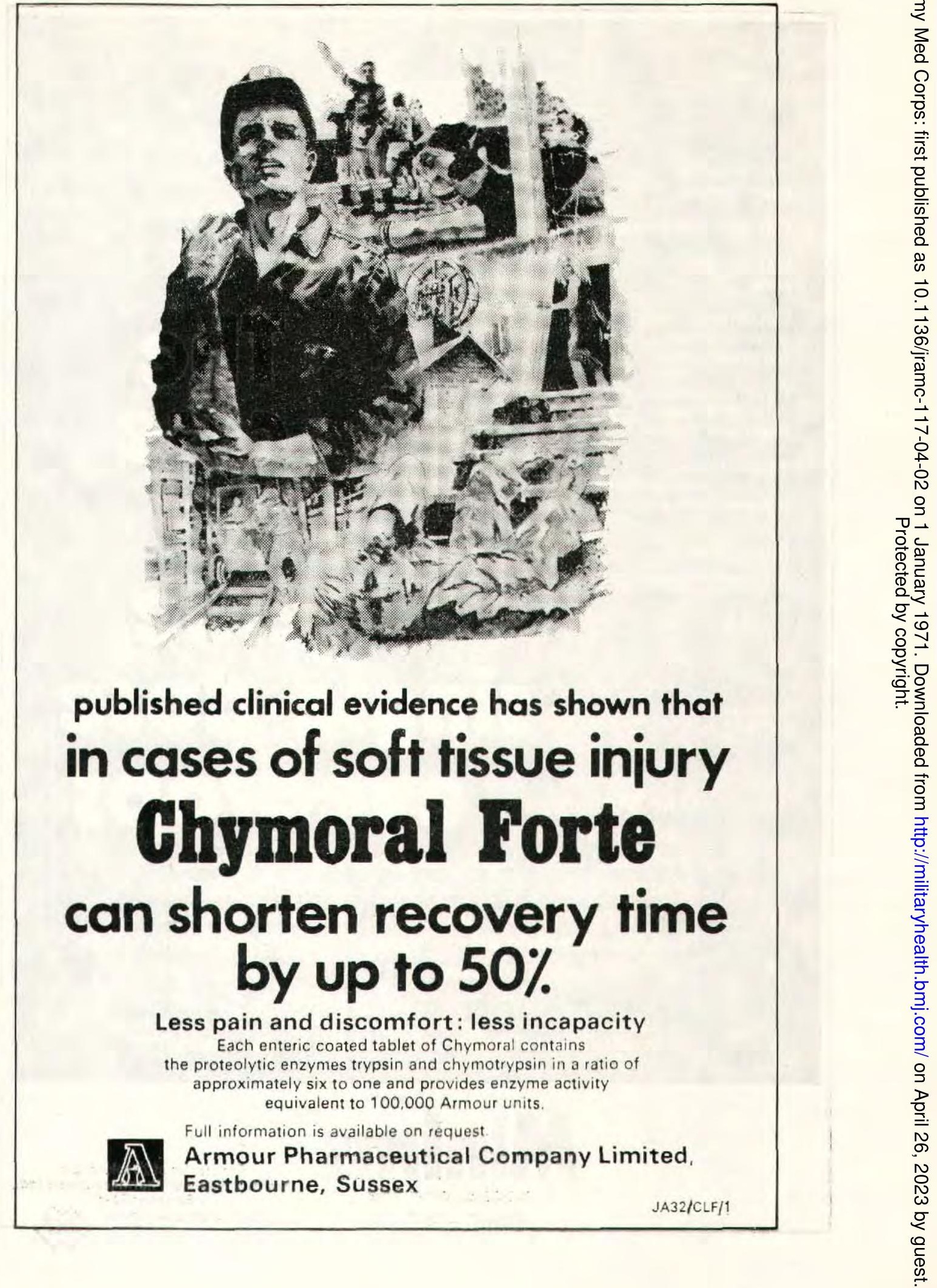




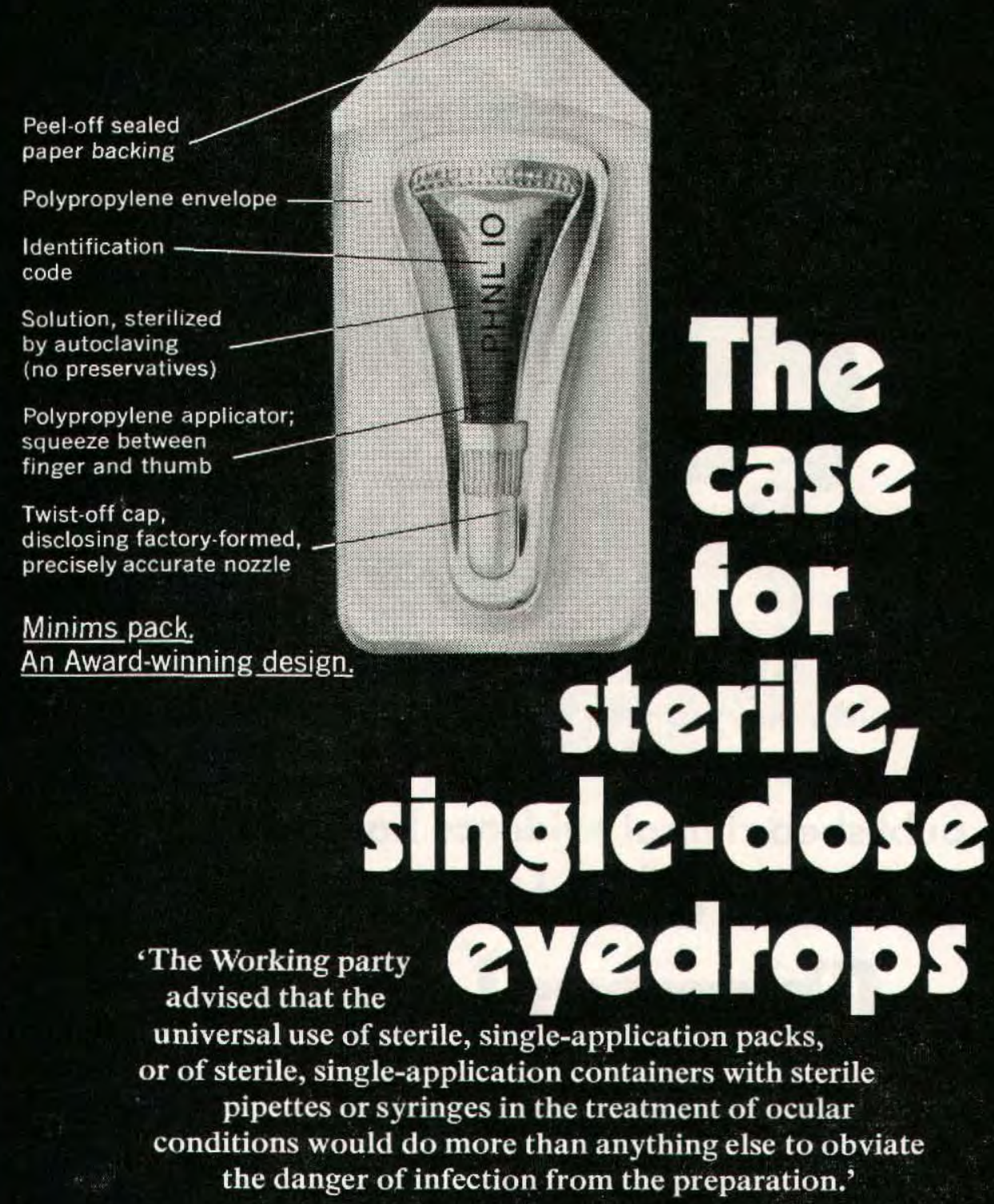

Preservation of Sterility in Ophthalmic Preparations used in Hospitals. Department of Health and Social Security, HM (69) 86, November 1969.

Second Generation

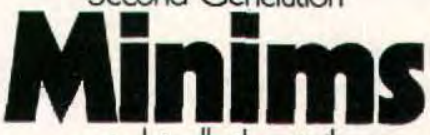

out-date all other sterile single-dose eyedrops

Send for list of 23 solutions to Smith \& Nephew Pharmaceuticals Ltd., Bessemer Road. Welwyn Garden City, Herts. 


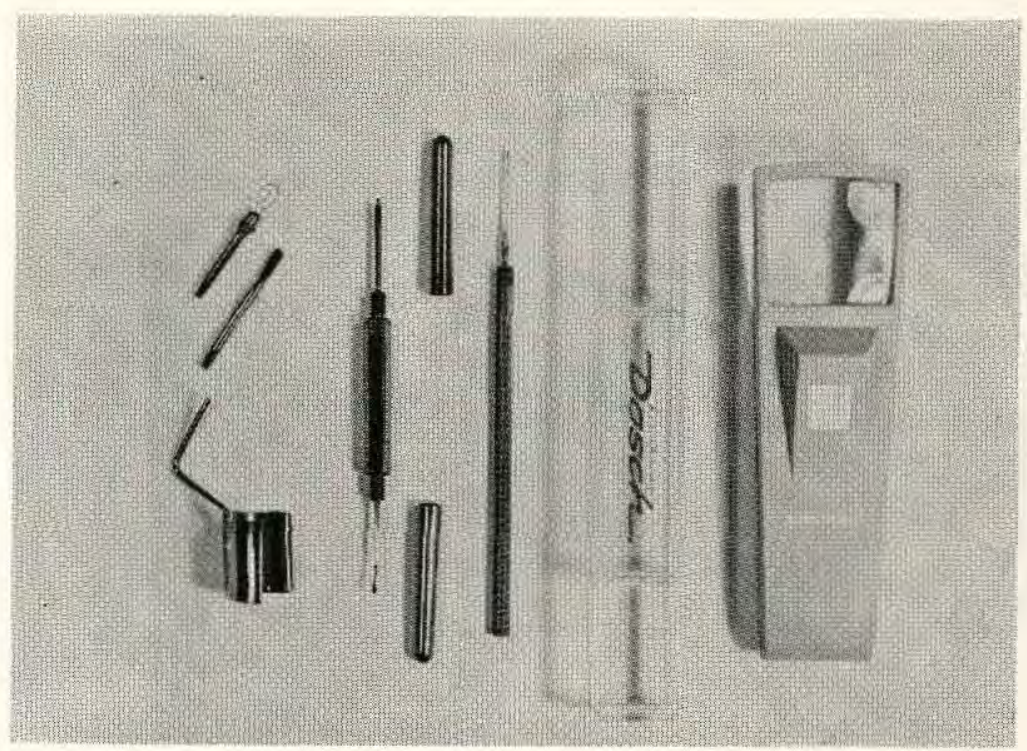

Fig. 6.

and hope that they will do so. Otherwise one must use a folding magnifying hand lens, holding the torch in the other hand.

\section{Corneal foreign bodies}

This problem will usually rear its head within the first week of arriving in a new location and lead to that degrading trip to the local hospital, or Royal Air Force station, unless one is prepared. To deal with them one needs the magnifier, sometimes fluorescein (Fluorets, Smith and Nephew), amethocaine eye drops (Minims), atropine and preferably an antiseptic, together with some tools for removing the foreign body.

\section{Pocket torch attachments}

The sable brush or nylon loop (Fig. 6 left) will remove some.

\section{Spuds}

More deeply imbedded bodies need to be dissected out, with minimal trauma. The issued instrument, 'spud, eye and needle' (Fig. 6 centre left $)$ will serve, although it is clumsy and unbalanced. My own preference (Fig. 6 centre right) has a longer handle which balances in the hand like a pencil. It is less portable, but rides securely in its plastic container.

Difficult foreign bodies, of course, are best dissected out under an operating microscope in hospital, if accessible.

\section{Thermometer cases}

It does not look very professional to go into a patient's house with one's thermometer in the case in which it was supplied (Fig. 7 third and fourth from right). There are various ways of overcoming this. If keeping it in fluid of some kind one needs a really leak-proof case, and a good one is shown (Fig. 7 second from right). As a small boy I always associated our family doctor with a strong smell of T.C.P., but this was 


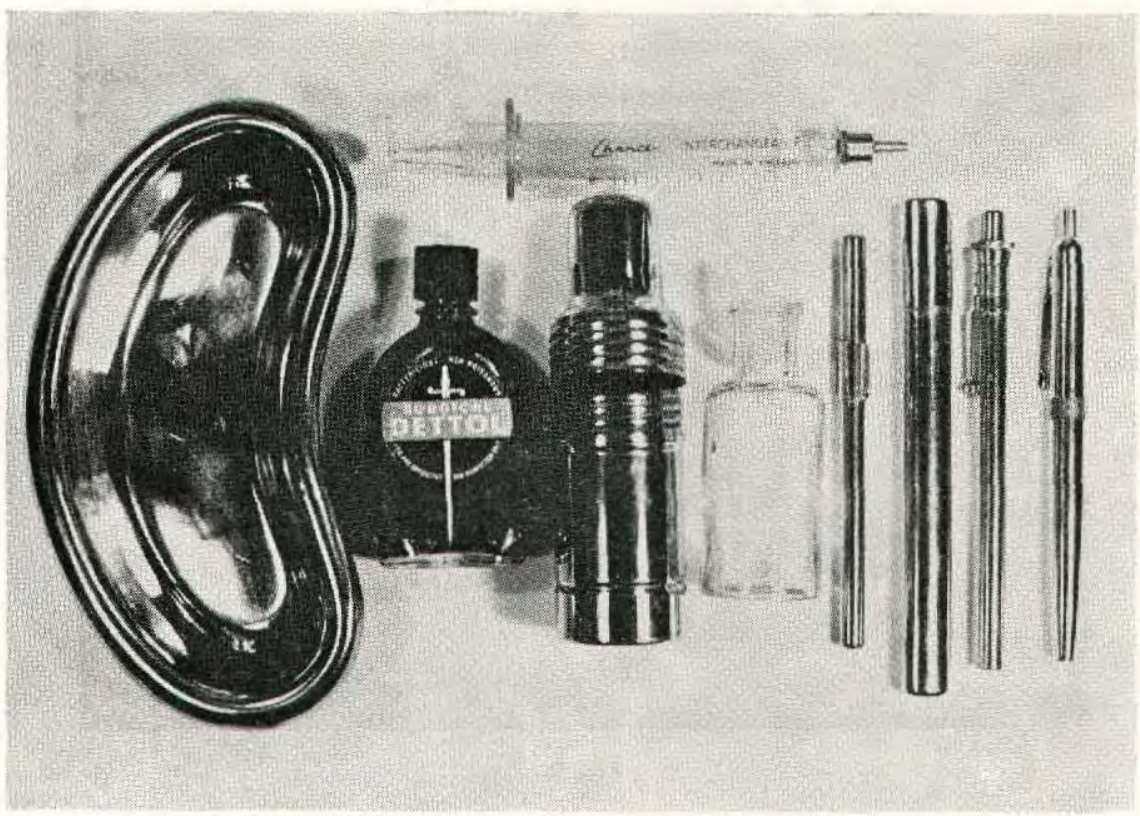

Fig. 7.

probably because the poor fellow's thermometer case was leaking. Alternatively, that on the extreme right of Figure 7, kindly provided by Rousel Laboratories, does not contain fluid, but neatly accepts the new, small centigrade thermometer in its retractable mount.

\section{Spirit-proof cases}

For skin swabbing (Fig. 7 centre right) should also be carried, unless one is fortunate to obtain one of the excellent miniature Dettol bottles (Fig. 7 centre left).

\section{Kidney dish}

A small stainless steel dish (Fig. 7 left) is handy for containing syringe and swabs at the bedside. Syringes should never be waved naked in the air, especially when treating children.

\section{Syringe}

In these days of plastic syringes one is inclined to forget that glass ones are still necessary, for example, for paraldehyde. They are also more precise and contain less air for intravenous injections, such as, aminophylline. The Chance type (Fig. 7 top) are accurately made, will last a long time, and repay their initial cost; surviving barrels or plungers will instantly and accurately mate with each other. Separate needles of the correct type for these syringes must be carried.

\section{Bandage scissors}

These small but necessary items are obtainable from Service sources (Fig. 8 left), but in my experience are almost invariably absent when one takes over an establishment. They are preferable to the large stretcher bearer scissors for dressings, and preferable 


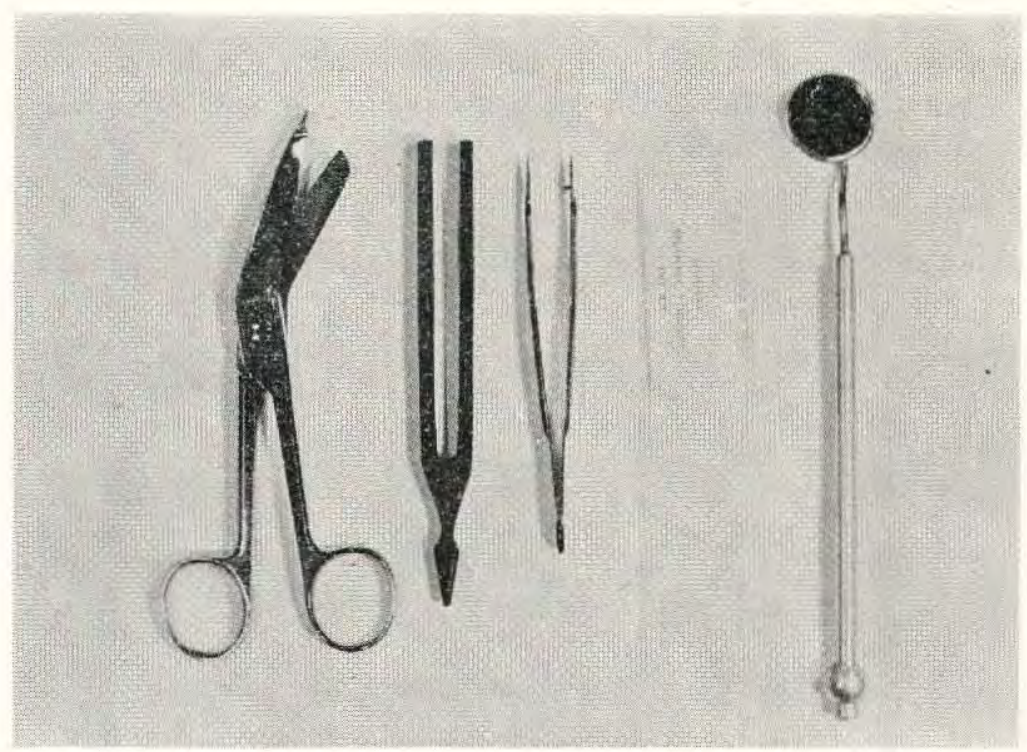

Fig. 8 .

too, with their lower blunt end, for removing circular turns from limbs, for example, elastoplast from sprained ankles. They are essential for removing some limb dressings, t uch as ichthyspaste bandages as used in varicose eczema. Even then, one has to be careful to keep the scissors in a vertical plane. 1 once made a gash about 3 inches long when slitting a viscopaste from a woman's oedematous leg; as the leg was almost insensitive she could not warn me.

\section{Tuning fork}

Absence of this item from the medical centre scale (except for Medical Boards) renders impossible the examination of nerve deafness. Possession of a small tuning fork (Fig. 8 centre left) obviates this difficulty.

\section{Splinter forceps}

Absence of this item, of course, means removal of more finger-nail than necessary. They used to be catalogued "Air Force only", but are now available to all. Unfortunately the issued ones are not sufficiently precise. They should be strongly made and have a prong on one blade to mate with a hole on the other, thus keeping the points in correct apposition, as in my example from Thackray (Fig. 8 centre right). The splinter, one hopes, is trapped in a groove between the points. Sometimes even these will not secure a strong enough grip and it is then necessary to remove more nail and apply mosquito forceps.

\section{Dental mirror}

This is useful for examining the retropharyngeal area as well as teetn (Fig. 8 right) -a not infrequent chore nowadays.

\section{Instrument case}

It is more professional to carry one's small instruments in a black leatherette 
zipped case, with washable lining (Figure 9). In addition, one will obviously carry several varieties of scalpel blades, Bard-Parker handle, forceps and scissors, including especially a good sharp-pointed pair for one's sole use in stitch removal, and a less sharp-pointed pair (Fig. 9 third from left) for general use.

\section{Sutures}

I have not touched on this subject at all, as I assume that a full range of material

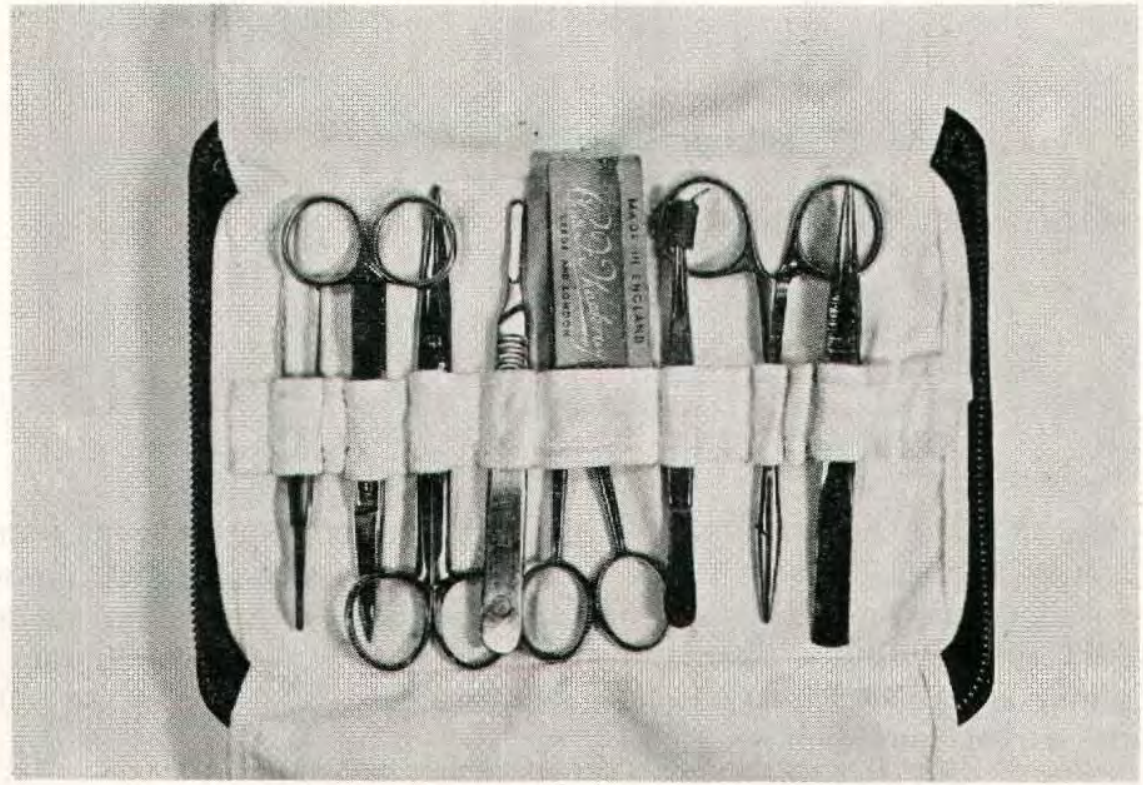

Fig. 9.

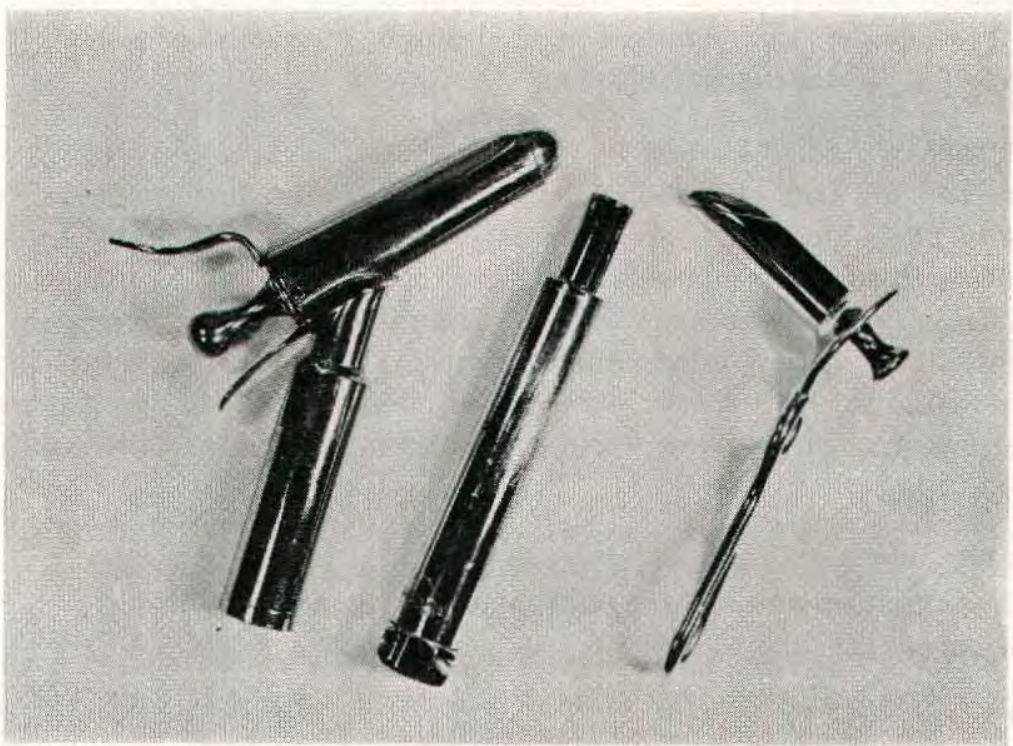

Fig. 10 . 
will be available. Especially for girls' faces, however, in case integrally threaded needles are not forthcoming, it is handy to have a curved hollow needle of the " perineal " type, but smaller, to avoid passing the eye of a needle through the facial skin.

\section{Proctoscopes}

It is useful to have a proctoscope with built-in battery handle (Fig. 10 left and centre). Personally I use this instrument for taking cervical smears too, as it is smaller to introduce, yet will accept the Ayre's wooden spatula. A miniature 'scope (Fig. 10 right) is necessary for the young.

\section{Sphygmomanometers}

In service practice there is much less occasion to carry a sphygmomanometer on domiciliary work, but my Aries model (Fig. 11 right) is smaller and lighter than the standard Accoson (Fig. 11 left). It is housed in a leather case, and its narrow cuff is appropriate for children. The mercury has to be zeroed prior to use. Nowadays, one would probably purchase a circular dial type for house visits.

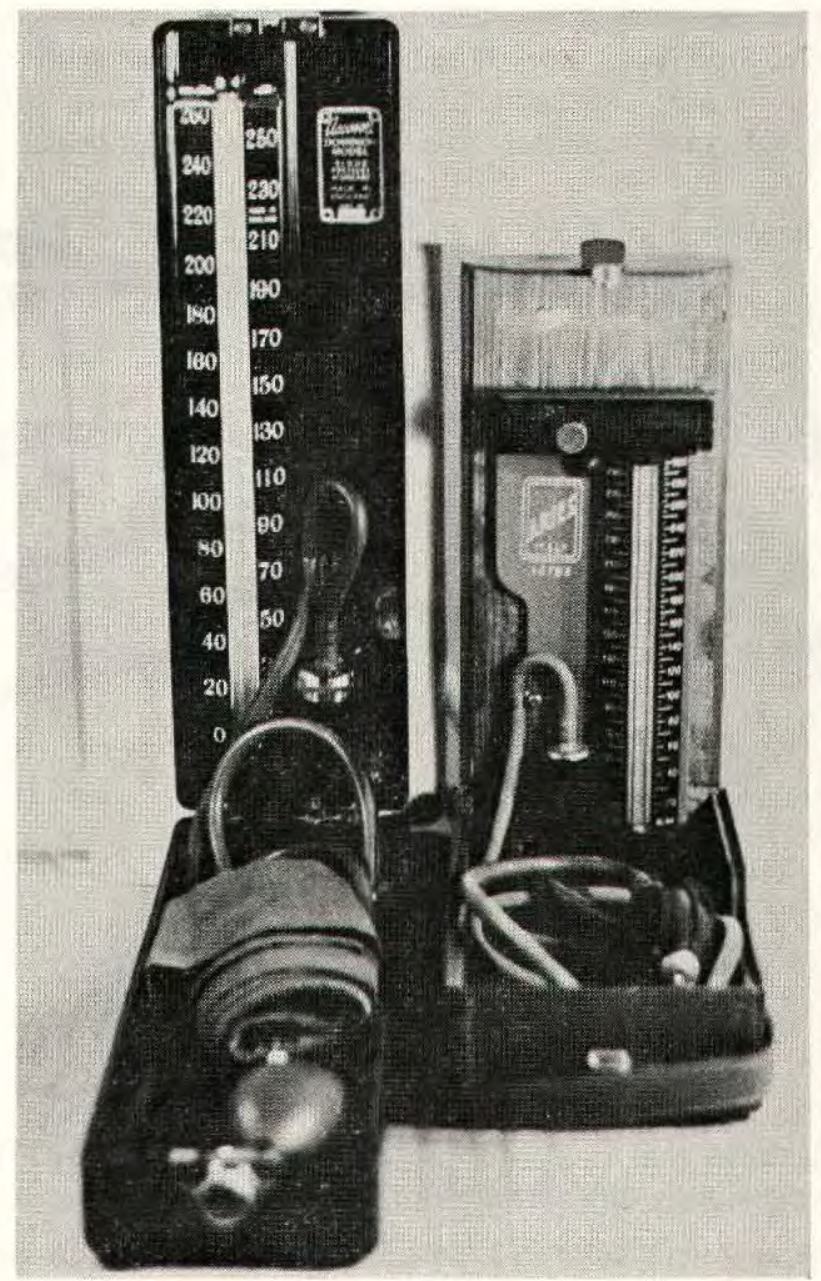

Fig. 11. 


\section{Pocket tape measure}

For Pulheems and life insurance this saves time in the eternal search, as it appears to be an attractive item.

\section{Stethoscopes}

The foregoing tools are what I consider should be in the general practitioner's armamentarium, exclusive of midwifery and gynaecological instruments, and in addition to a stethoscope. What of that symbol itself? It is probably less necessary than some other tools, especially illuminants. The actual type of stethoscope carried by the general practitioner is not of great importance, but some varieties are shown in Figure 12. If our modern medico is going to invest in a Littman, he will not be interested in the others, and he had best accustom himself to its use as a routine. If slipping the chest piece under a woman's clothes is considered an advantage, the plain diaphragm (Fig. 12 left) will suffice. If a bell is desired as well as a diaphragm, it can be obtained much more cheaply than a Littman (Fig. 12 right). A folding head-piece (Fig. 12 top) will be less damaging to one's clothes (a special pocket should always be tailored in). Rubber ear pieces are more comfortable, but less hygienic and still not as comfortable as the Littman. For paediatric work one should have a chest-piece with a small bell and diaphragm (Fig. 12 top left ), attached to a long single rubber tube for introducing through the circular hole in perspex incubator covers, in order to minimise loss of oxygen.

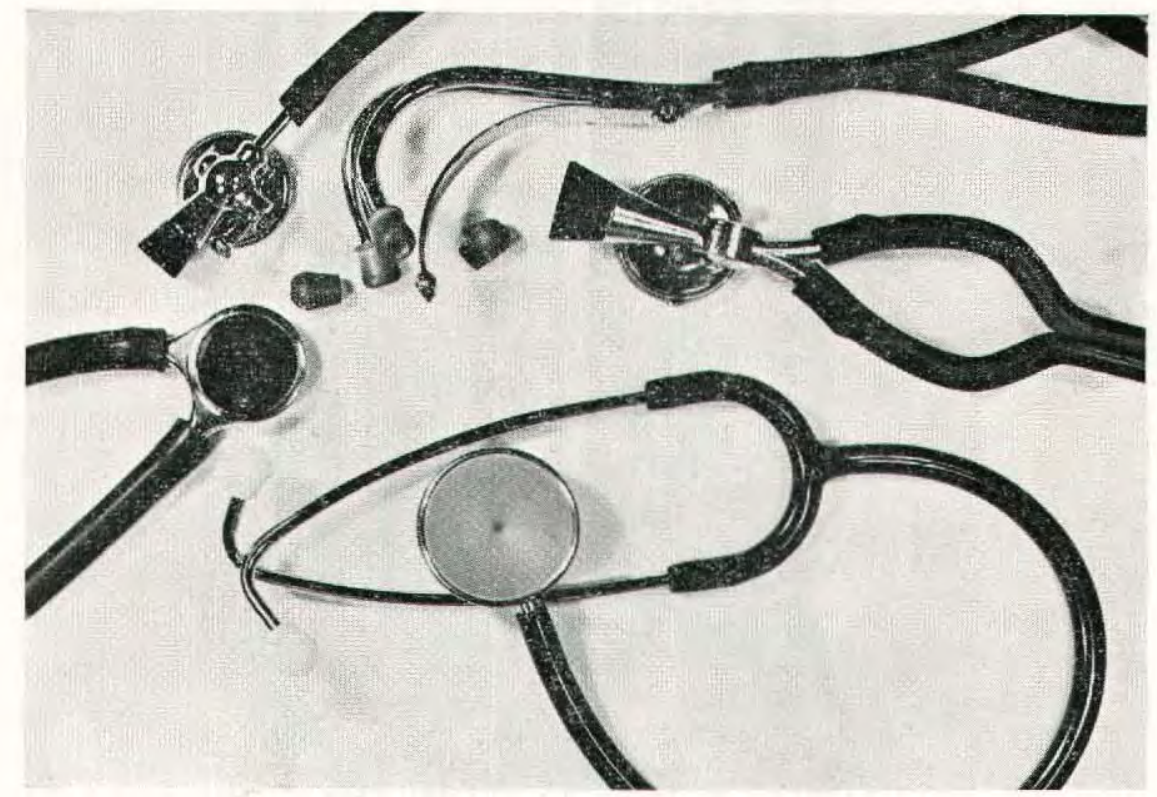

Fig. 12.

\section{Utilisation and carriage}

It is not suggested that every item should always be carried. The requirements for active service obviously differ from normal general practice.

On operations I usually carry the items I require along with my camera equipment in my "black box". This is a moisture and dustproof miniature steel trunk measuring 
$50 \times 25 \times 15 \mathrm{~cm}$, which cost about five pounds, and travels with me on the aircraft, wrapped in hessian. More sophisticated versions with rounded corners and interior foam padding can now be obtained from photographic dealers, but at higher cost. Lacon boxes are too large for personal use, although excellent for field ambulance equipment.

For drugs and instruments in general practice I use a normal black bag with separate compartments, rather than the issued version, which is too wide. The issue is in fact a midwifery bag, and its dimensions are intended to contain the forceps. It is clumsy to carry and lacks proper compartments. Those who think it is ideal should carry it down a dark lane on a wet night. As there is a limit to the weight I want to carry, I keep a second bag to contain the surplus, especially items required for emergency medical procedures. My third bag is a fully equipped midwifery outfit, sadly only for emergency use nowadays.

\section{Discussion}

There is little doubt that availability of the equipment listed above will improve the Army general practitioner's efficiency. The question is whether it should be his own property or issued from Service sources, bearing in mind that in a salaried service none of the outlay can be recouped from the Revenue (in National Health Service practice one can claim for the cost of instrument replacements to be offset against gross income).

For each Medical Centre there is a scale, which may or may not be complete at the time one takes over. Replacements and some additional items can also be obtained, but this takes time. Success in this field depends on the skill of the indenting officer, the contents of the medical depot, luck and time available. Some establishments have branch surgeries (families clinics), not allowed for in the normal scale. Again, certain delicate items like splinter forceps and foreign body extractors are unsuitable for general issue because they would soon be rendered unserviceable.

A big advantage of having one's own instruments is that they are kept all together, and are known to be available on moves. On exercises or active service, one gets no more than one carries, generally speaking. Indents are not necessarily handled with appropriate urgency.

Even in hospital casualty departments one will generally lack the bandage scissors, splinter forceps and some of the ophthalmic instruments, and eye departments are not open at night and weekends.

Apart from the auriscope/ophthalmoscope none of the items I have dealt with is unduly expensive, but should be collectively insured, with a declared value for the auriscope set.

\section{REFERENCES}

British Joint Services Catalogue of Medical Equipment.

Regulations for the Medical Services of the Army (1954). Section 15, Scales of Medical Equipment. 